\title{
Exploring Persona-Scenarios - Using Storytelling to Create Design Ideas
}

\author{
Sabine Madsen $^{1}$ and Lene Nielsen ${ }^{2}$ \\ ${ }^{1}$ Department of Communication, Business and Information Technologies, \\ Universitetsvej 1, 43.2, \\ 4000 Roskilde \\ ${ }^{2}$ Snitker \& Co. Bredgade 21B, \\ 1260 Copenhagen K, Denmark \\ sabinem@ruc.dk, ln@snitker.com
}

\begin{abstract}
This paper explores the persona-scenario method by investigating how the method can support project participants in generating shared understandings and design ideas. As persona-scenarios are stories we draw on narrative theory to define what a persona-scenario is and which narrative elements it should consist of. Based on an empirical study a key finding is that despite our inherent human ability to construct, tell, and interpret stories it is not easy to write and present a good, coherent, and design-oriented story without methodical support. The paper therefore contributes with guidelines that delineate a) what a design-oriented persona-scenario should consist of (product) and b) how to write it (procedure) in order to generate and validate as many, new, and shared understandings and design ideas as possible (purpose). The purpose of the guidelines is to facilitate the construction of persona-scenarios as good, coherent stories, which make sense to the storytellers and to the audience - and which therefore generate many, new, and shared understandings and design ideas.
\end{abstract}

Keywords: Storytelling, personas, scenarios, narrative theory, IT systems development, e-reporting.

\section{Introduction}

IT systems development is a complex endeavor with a number of persistent problems [1]. The process often involves diverse participants that have to work together and share their knowledge, but the mechanisms where by individuals share and integrate their expertise is not well understood [2]. Moreover, simply asking future users to specify requirements and come up with innovative ideas for the IT system will not suffice [3] as it is difficult for people to talk about and relate to a non-existing artifact. For requirements determination this means a significant bias toward requirements based on current practices, already available information, recent events, and inference from small samples of events [3]. The analyst and user have to compensate for these biases, e.g., via methods that provide guidance for overcoming them [3]. In addition, it is difficult for users to describe requirements in terms of facts, fields, rules, and 
algorithms $[4,5]$. One suggestion is therefore that it might be useful to focus on, interpret, and elicit requirements from the stories of existing and hypothetical practices that prospective users tell during requirements interviews [5].

Another suggestion is to use scenarios, which have been described as easy to relate to and remember as they draw on our human ability to individually and jointly make sense of, arrange, and convey information in a narrative form [5]. There are many different types of scenarios. We make a distinction between persona-scenarios that are based on personas descriptions, and scenarios that are not. Our focus is on the former.

The personas method and its belonging scenario part have gained popularity within systems development. However, even though the persona-scenario is a vital part of the persona method, it is not commonly agreed and well defined what constitutes a persona-scenario; what types of understandings and design ideas persona-scenarios generate; and how they might be applied to generate as many new understandings and design ideas as possible. This is in part due to the scant literature on the topic. Numerous practitioner reports that describe experiences with the method can be found on the Internet, but there are few empirical studies at journal level and only three complete books [6],[7],[8] about the persona method. In other words, the persona literature is conceptually and empirically weak with regard to the scenario aspect of the method.

To contribute to the literature about the persona method, we set out to study and answer the following research question: how can the persona-scenario method be used to generate as many, new, and shared understandings and design ideas as possible?

To answer the research question we first look at scenarios as described in the persona literature and compare the literature to narrative theory. From this we define a persona-scenario in terms of narrative elements. Then we look at and discuss an empirical study [9] to extract experiences. In the conclusion we summarize the narrative elements and empirical experiences in the form of a set of guidelines. We wish to explore the persona-scenario method as a means for supporting groups of project participants in constructing and performing multiple stories that complement each other in generating many, new, and shared understandings, and design ideas during requirements determination. As such, our study builds on [4] research into how people use narratives to convey information about requirements.

\section{Presenting Personas and Scenarios}

A persona is a description of a fictitious user, based on data from user research. In IT systems development the persona description is used as the foundation for outlining a persona-scenario that investigates the use of an IT system from the particular persona's point of view.

The scenario term and method is not a novelty. It has previously been used in the Scenario-Based Engineering Process that combines business process reengineering with systems development [10]. It has also been used to refer to more abstract illustrations of systems use, such as use cases. Even though scenarios have been around for some time there is no single definition in common use [11]. Some definitions are that scenarios are: "descriptions of natural, constructed or imagined contexts for userproduct interactions." [12] p. 153, "a description of a set of users, a context and a set 
of tasks that users perform or want to perform. A scenario sketches future technologies" [13] p. 13, or that they are stories about people and their activities [14] p.17. At the broad level, there seems to be agreement that scenarios are stories and this is also the view we adopt in this paper.

Cooper [6] explains that both scenario-based design and use cases miss the central aspect of understanding the user. Scenario-based design focuses on describing how users accomplish tasks and sees the user as an abstracted role, while use cases treat all possible user interactions as equally likely and important, lack description of context, and use variables and class names instead of more literal descriptions. In contrast, persona-scenarios view the user as a particular person with emotions, actions, and needs and it is the persona who is the focal point of the persona-scenario, not the IT system. However, even though this is commonly recognized, there is no unanimous definition of what a persona-scenario is and what it consists of.

First of all the persona method authors suggest different types of personascenarios. Cooper [6] suggests a progression from initial, high-level persona-scenarios to more and more detailed ones with increasing emphasis on the user-product interaction. As a part of this progression, they distinguish between problem scenarios, which are stories about a problem domain as it exists prior to technology introduction, and design scenarios that convey a new vision of the situation after technology introduction. Pruitt \& Adlin [7] refer to Quesenbury's [15] definition of different types of personas and to scenarios with different levels of detail placed in a continuum between evocative and prescriptive scenarios as well as along the development process. Mulder \& Yar [8] focus exclusively on web development and only propose one type of scenario that describes a persona's journey through a website. Second, the method authors provide different lists of elements that could/should be included in a 'complete' or 'good' scenario. Between the authors [7, 8, 10, 15] the lists of scenario elements are somewhat similar, but only [15] and [8] explain the elements that should be included in a scenario and this only in a brief manner. [8] state that the scenario elements they outline are the classic components of storytelling. However, they do not explain what classic storytelling is.

In general, the persona literature is clearly inspired by, but does not explicitly reference narrative theory. We suggest that it is relevant to look more closely at the narrative aspect of persona-scenarios and to draw more explicitly on narrative theory in doing so.

\section{Presenting Narrative Theory}

We draw on narrative theory positioned within the cognitive and the technical approaches to the study of stories [16]. The cognitive approach describes narrative as an operation of the mind, as a way to create meaning. The technical approach defines narratives and narrative elements. Thus, narrative is considered both a process (mental story construction) and a product [16]; both performance and text [17].

Narrative theory refers to the narrative as consisting of the overall story and the narrative discourse [18]. The overall story is the events in sequence, bound by the laws of time and proceeding in one direction starting with a beginning, passing through the middle and arriving at the end. The narrative discourse is the representation of events. 
The narrative discourse is not bound by the laws of time and can present the events in any order [18].

It is by no means an easy task to define which elements a narrative consists of. Discussions range from how the smallest elements of a narrative are defined to whether media should be considered. We draw on the strand of theory that argues that a narrative has to have more than one event and that these events have to be causally connected [19], [20], [16], [21]. Moreover, for a text (in the broadest sense of the word) to qualify as a narrative it must [26]:

Create a world and populate it with characters and objects; the world must undergo changes of state that are caused by non-routine physical events: either accidents/happenings or deliberate human action.

Allow the reconstruction of an interpretive network of goals, plans, causal relations, and psychological motivations around the narrated events.

According to the prototypical story form [22] a story begins with a setting in which characters, location, problems, and time is presented. After this presentation, one or more episodes follow, each having a beginning and a development towards a goal. In the opening episode, the character reacts to the beginning events, sets a goal, and outlines a path to reach the goal. Each episode focuses on the goal, attempts to reach the goal, and obstacles for reaching the goal. The attempts are understood as the causes to the outcome. Each episode links to the overall story, thereby creating the plot.

\section{The Scenario in a Narrative Theory Perspective}

Table 1 presents an overview of the story form and our 'translation' here of to a persona-scenario context. The translation of narrative theory to a persona-scenario context address the theoretical gap and confusion about what a persona-scenario is and should consist of.

Table 1. The story form and its elements

\begin{tabular}{|c|c|}
\hline NARRATIVE ELEMENTS & $\begin{array}{l}\text { NARRATIVE ELEMENTS IN A } \\
\text { PERSONAS-SCENARIO }\end{array}$ \\
\hline $\begin{array}{l}\text { Character(s): a protagonist as well as } \\
\text { minor characters. A character can be any } \\
\text { entity that has agency, involved in the action. }\end{array}$ & $\begin{array}{l}\text { In persona-scenarios the persona is the } \\
\text { protagonist. }\end{array}$ \\
\hline $\begin{array}{l}\text { Time: both the time in which the actions } \\
\text { take place, e.g. the future, and the story } \\
\text { development over time - beginning, middle, } \\
\text { and end. }\end{array}$ & $\begin{array}{l}\text { Most persona-scenarios are set in present } \\
\text { time but they can also concern a distant } \\
\text { future. } \\
\text { The story time can last minutes, days, } \\
\text { months, etc. }\end{array}$ \\
\hline $\begin{array}{l}\text { Problem: a loss, a need, a lack of } \\
\begin{array}{l}\text { something, an obstacle to overcome, a } \\
\text { conflict. }\end{array}\end{array}$ & The persona has a problem. \\
\hline $\begin{array}{l}\text { Setting: presentation of characters, } \\
\text { location, problems, and time. }\end{array}$ & $\begin{array}{l}\text { The narrative begins with a presentation } \\
\text { of the persona, his or hers problems, the } \\
\text { place where the action takes place as well as } \\
\text { the time (present time/distant future). }\end{array}$ \\
\hline
\end{tabular}


Table 1. (Continued)

\begin{tabular}{|c|c|}
\hline TIVE ELEMENTS & $\begin{array}{l}\text { NARRATIVE ELEMENTS IN } \\
\text { PERSONAS-SCENARIO }\end{array}$ \\
\hline $\begin{array}{l}\text { Opening episode: the character reacts to } \\
\text { the problem, sets a goal, and outlines a path } \\
\text { to the goal. }\end{array}$ & $\begin{array}{l}\text { The persona defines the goal and starts to } \\
\text { act. }\end{array}$ \\
\hline $\begin{array}{l}\text { Episodes: development toward the goal. } \\
\text { Episodes consist of: } \\
\text { Beginning } \\
\text { Attempts } \\
\text { Events (accidents, obstacles, happenings, } \\
\text { deliberate human actions) } \\
\text { Development } \\
\end{array}$ & $\begin{array}{l}\text { The persona-scenario develops through a } \\
\text { sequence of episodes that concern the } \\
\text { problem, the goal and the attempts to reach } \\
\text { the goal, the events involved in these } \\
\text { attempts and the obstacles hindering } \\
\text { fulfillment of the goal. }\end{array}$ \\
\hline $\begin{array}{l}\text { Resolution: the problem is solved and the } \\
\text { goal is reached - or not. }\end{array}$ & $\begin{array}{l}\text { There are two types of persona-scenarios } \\
\text { - one where the problem is solved and the } \\
\text { goal is reached, and one where they are not. }\end{array}$ \\
\hline $\begin{array}{l}\text { Plot: the linkage and order of the } \\
\text { episodes. }\end{array}$ & $\begin{array}{l}\text { Most persona-scenarios are presented in a } \\
\text { linear manner, without deviations from the } \\
\text { story time. }\end{array}$ \\
\hline $\begin{array}{l}\text { Overall story: starts with a beginning, } \\
\text { goes through a middle, and arrives at the end. } \\
\text { The overall story is sensitive towards } \\
\text { what is considered ordinary social practice } \\
\text { within a given culture and explains } \\
\text { deviations from accepted social practice. }\end{array}$ & $\begin{array}{l}\text { Each episode links to and has to be } \\
\text { meaningful in relation to the overall story. } \\
\text { The persona-scenario has to explain why } \\
\text { non-routine actions and events happen and } \\
\text { how they are dealt with. }\end{array}$ \\
\hline $\begin{array}{l}\text { Narrator's perspective: The narrative is } \\
\text { told by someone. }\end{array}$ & $\begin{array}{l}\text { Most persona-scenarios are told in third- } \\
\text { person allowing the narrator to be } \\
\text { omnipotent. }\end{array}$ \\
\hline
\end{tabular}

\section{Case Description and Analysis}

It is the strategy in Denmark that all communication between companies and government is to be digital in the near future. Virk.dk is part of this strategy. Virk.dk is a portal that contains more than 1500 forms, which can be used by companies to report to governmental bodies in Denmark. In the future all forms must be reported digitally. Virk.dk has existed since 2002, but has not been widely used due a lack of focus on ereporting. This paper reports from the redesign of the portal. Early in the redesign process it was decided to use the persona method as it was the hope that user centered methods could help overcome the problems with lack of use. This paper concerns a full-day persona-scenario workshop. 16 workshop participants were chosen by the customer as being key stakeholders in the development process. The participants were customer representatives, graphic designers, and programmers and covered several areas such as project management, marketing/content, user rights, user interface design, and IT development. The aim of the workshop was to get the workshop participants to use the persona-scenario method to create insight into users as well as new design ideas. The 16 workshop participants were divided into four groups. The four groups were introduced to the persona-scenario method, how to write a scenario that follows the story form, and, briefly, to each of the story elements. Each group got a 
short text with a start situation for their persona, developed a persona-scenario, and presented it to the other groups. Now a short overview of the analysis of the four groups' scenarios is presented (the research approach and case analysis is reported in full elsewhere, see [9]).

\section{Group 1: Karina reports digitally}

The first group received the following text: "Karina has a digital signature and would like to report wage statistics..." (Excerpt from start situation). The group chose not to write anything during the scenario development session. The oral narrative was fragmented with regard to the overall story as the setting and the episode was described in abstract terms. The narrative discourse was also fragmented as the presenter was unable to keep causality due to the lack of a written scenario. This made it difficult for the audience to create meaning from the narrative. Design ideas occurred at the few times when the episode developed towards the goal via concrete events. No additional understanding of the user was achieved.

\section{Group 2: Michael looks for information}

The second group received the following start situation: "It is after closing time and Michael tries to find information about a new country he is importing from." (Excerpt from start situation). The group explored how their persona, Michael, a shop-keeper with low IT skills, uses Virk.dk. The story contains three episodes of which only the two first are driven forward by the goal. In the third episode Michael gives up. The scenario becomes a story in which the problem is not overcome and the goal not reached. The written scenario was very short, while the oral narrative was more enhanced. In both cases the overall story related to the persona and he was prominent in the plot, whereas Virk.dk received less attention. Moreover, both narratives were coherent and easy to make sense of with regard to the overall story and the narrative discourse. However, the future Virk.dk's possibilities for helping Michael overcome the initially stated problem, namely his low IT skills, were not explored, because the group had decided to describe the present Virk.dk.

\section{Group 3: Dorte uses Virk.dk for the first time}

The third group got the following start situation: "Dorte has finally received her digital signature... and would like to report trainee wages." (Excerpt from start situation). The group wrote a scenario centered round their persona, Dorte, a secretary in a small company, who invites her son to help her do her first e-report. During the presentation, the written scenario was read out load. The scenario was a coherent story that established an understanding of Dorte and her needs. It had intense character descriptions of thoughts and feelings. Furthermore, the episodes and events were casually connected and the plot was easy to follow. However, as the son became the means of problem solving, the story never explored what the IT system could do to support Dorte. The group presented afterthoughts as they were aware that they had written an unrealistic scenario, where they did not explore the obstacles Dorte encountered.

\section{Group 4: Jesper reports an instance for a customer}

The fourth group received the following text: "Jesper sits in his office and has to use the new Virk.dk for the first time..." (Excerpt from start situation). The group wrote a story that introduced the persona, Jesper, an accountant. The opening episode was fully presented, but as the narrative discourse progressed the presenter shifted in and 
out of the story sometimes forgetting about Jesper in favor of technical aspects of the current and possible future version of Virk.dk. This made it challenging for the audience to reconstruct the overall story. The digression to technical description were also present in the written story, where focus shifted back and forth between the persona, the IT system, and design activities.

\section{Discussion}

Narrative theory [18] suggests that humans have an intuitive understanding of and expect stories to follow the story form. The case study analysis showed that for scenario writers once the story is started it develops in its own course, i.e. when it has been decided to focus on the present IT system and a son has been invited to help. When a certain setting and the elements here of are introduced they can have unexpected consequences for the story and can lead to plots and endings that are too simplistic - from a design perspective. Such plots and endings are intuitively perceived as unconvincing, both by the scenario writers and the audience. However, the case study also showed that it is much easier to instinctively interpret a scenario's plausibility than it is to write a scenario that follows the story form, and solves the persona's problems in a design-oriented way.

To construct a convincing design scenario, we propose that while the persona is the protagonist, the future IT system has to play a prominent role as well. But how? [23] argue that it is essential to explicitly conceptualize the IT artefact. We agree. However, when it comes to persona-scenarios the IT artifact is a part of the story and therefore, it also has to be conceptualized as a part of the narrative elements that make up a story. Thus, within the story and with regard to the narrative elements, the IT system is a part of the events - rather than a character or tool-like object. This also means that the more detailed and concrete the events are and the more they address obstacles and design-oriented ways of overcoming the obstacles, the more concrete the future IT system and design ideas for the future IT system stand out within the story and get validated from the persona's point of view. Therefore, we also recommend that in design scenarios the problem should always be solved and the goal should always be reached.

The implications of the presented findings for research and practice are as follows. The existing research on storytelling tends to stress how easy and natural it is for people to construct, tell, and interpret stories. However, our case analysis shows that it is difficult to write and present a good, coherent and design-oriented story without methodical support. This suggests that more theoretical and empirical research is needed to investigate what kind of theories, methods, and detailed guidelines that are needed to support the practical work of generating IT systems requirements via storytelling. In particular we suggest that more research is needed to refine the personascenario method by providing clearer definitions of concepts and 'how-to' guidelines based on narrative theory and narrative analysis of the content and performance of persona-scenarios. For practice, our research suggests that it is important to design persona-scenario workshops so that they are organized around a focus on the story form and to provide guidelines for working with the story form. 


\section{Conclusion}

In this paper we investigate persona-scenarios as a mechanism for supporting the work of diverse IT project participants in creating design ideas. We conclude that because persona-scenarios are stories and thus, draw on our human ability to intuitively arrange and understand information conveyed in a narrative form they allow for interdisciplinary knowledge sharing and creation of a common understanding about personas and their use of the IT system. However, despite our inherent human ability to construct, tell, and interpret stories, it is not easy to write and present a good, coherent story that generate many new understandings and design ideas. A set of guidelines concerning how to construct and present persona-scenarios is therefore needed.

Narrative theory suggests that stories that are in line with the story form and its narrative elements are easier to relate to, remember and in general more convincing. Narrative analysis of the content of four persona-scenarios supports this and further shows that:

- In order to generate design ideas the events in the persona-scenario have to be described in a concrete and detailed manner.

- In order to generate as many new understandings and design ideas as possible the persona's problem presented in the beginning of the personascenario as well as the obstacles the persona encounters as events unfold should be investigated and solved within the story. Thus, design scenarios should have a happy ending.

- In order to validate understandings and design ideas from the persona's point of view the persona-scenario should concern the use of the future IT system.

The IT system is a part of the events and becomes tangible in the interaction that takes place between the user and the IT system. Therefore, the more concrete and detailed the events are and the more they emphasize obstacles and design-oriented ways of overcoming the obstacles, the more concrete aspects of and design ideas for the future IT system will stand out and get validated from the persona's point of view.

Below, we present a set of theoretical and empirically grounded guidelines that outline a) the narrative elements that a persona-scenario should consist of (see Table 2 literature-based findings are shown in normal text, case study findings in italic) and b) a procedure for how to construct and present persona-scenarios to generate as many, new, and shared understandings and design ideas as possible.

In order to write and work with persona-scenarios in future workshops we suggest the following procedure:

Introduction: The workshop leader a) introduces the workshop participants to the persona-scenario method and the distinction between problem and design scenario as well as the story form and the guidelines presented in Table 2 and b) hands out the scenario start situations and the guidelines in Table 2.

Preparation: The workshop participants discuss the guidelines and note down keywords. 
Table 2. What a design-oriented persona-scenario should consist of

\begin{tabular}{|c|c|}
\hline $\begin{array}{l}\text { Narrative } \\
\text { elements }\end{array}$ & Narrative elements in Persona-Scenarios \\
\hline Character(s) & The persona should be the protagonist, not the IT system. \\
\hline Time & $\begin{array}{l}\text { Most persona-scenarios are set in present time but they can also concern a } \\
\text { distant future. The story time can last minutes, days, months, etc. } \\
\text { The persona-scenario should concern the use of the future IT system. }\end{array}$ \\
\hline Problem & $\begin{array}{l}\text { The persona has a problem. A problem can be a loss, a need, a lack of } \\
\text { something, an obstacle to overcome, a conflict, etc. } \\
\text { The problem should be investigated and solved within the story. }\end{array}$ \\
\hline Setting & $\begin{array}{l}\text { The persona-scenario should begin with a presentation of the persona, his or } \\
\text { hers problems, the place where the action takes place as well as the time } \\
\text { (present time/distant future). }\end{array}$ \\
\hline $\begin{array}{l}\text { Opening } \\
\text { episode }\end{array}$ & In the opening episode, the persona should define the goal and start to act. \\
\hline Episodes & $\begin{array}{l}\text { The persona-scenario should develop through a sequence of episodes that } \\
\text { concern the problem, the goal and the attempts to reach the goal, the events } \\
\text { involved in these attempts, and the obstacles hindering fulfillment of the goal. } \\
\text { Events have to be described in a concrete and detailed manner. } \\
\text { The IT system is a part of the events and it (only) becomes tangible in the } \\
\text { interaction that takes place between the user and the IT system. } \\
\text { Obstacles should be overcome as a part of the events to as high a degree as } \\
\text { possible. }\end{array}$ \\
\hline Resolution & In design scenarios, the problem should be solved and the goal reached. \\
\hline Plot & $\begin{array}{l}\text { Most persona-scenarios are presented in a linear manner, without deviations } \\
\text { from the story time. }\end{array}$ \\
\hline Overall story & $\begin{array}{l}\text { Each episode should link to and be meaningful in relation to the overall } \\
\text { story. } \\
\text { The persona-scenario should explain why non-routine actions and events } \\
\text { happen and how they are dealt with. }\end{array}$ \\
\hline $\begin{array}{l}\text { Narrator's } \\
\text { perspective }\end{array}$ & $\begin{array}{l}\text { Most persona-scenarios are told in third-person allowing the narrator to be } \\
\text { omnipotent. }\end{array}$ \\
\hline
\end{tabular}

Writing: The workshop participants write the persona-scenario, using the keywords.

Analysis: The workshop participants analyze the written persona-scenarios in accordance with the narrative elements and guidelines outlined in Table 2. Special attention should be given to whether the initially stated problem and encountered obstacles are defined, investigated, and solved in a convincing, design oriented way within the story. Based on the analysis, the persona-scenarios are revised.

Requirements determination: The written persona-scenarios are read out loud, and from each persona-scenario, understandings, design ideas, and requirements are collaboratively extracted by the scenario writers and the audience.

More empirical research is needed to investigate and understand how the guidelines in Table 2 can best be used and how an intermediate step, where the written persona-scenarios are analyzed in accordance with the story form and its elements, will affect the experience and the understandings and design ideas generated. 


\section{References}

1. Kautz, K., Madsen, S., Nørbjerg, J.: Persistent Problems and Practice in Information Systems Development. Information System Journal 17, 217-239 (2007)

2. Gazan, R.: Imposing Structures: Narrative Analysis and the Design of Information Systems. Library \& Information Science Research 27, 346-362 (2005)

3. Davis, G.D.: Strategies for Information Requirements Determination. IBM Systems Journal 21(1), 3-30 (1982)

4. Alvarez, R., Urla, J.: Tell Me a Good Story: Using Narrative Analysis to Examine Information Requirements Interviews during an ERP Implementation. The DATA BASE for Advances in Information Systems 33(1), 38-52 (2002)

5. Carroll, J.M.: Making Use - Scenario-Based Design of Human-Computer Interactions. MIT Press, Cambridge (2000)

6. Cooper, A., Reimann, R., et al.: About Face 3: The Essentials of Interaction Design. Wiley, Indianapolis (2007)

7. Pruitt, J., Adlin, T.: The Persona Lifecycle: Keeping People in Mind Throughout Product Design. Morgan Kaufmann, San Francisco (2006)

8. Mulder, S., Yaar, Z.: The User Is Always Right: A Practical Guide to Creating and Using Personas for the Web. New Riders Press (2006)

9. Madsen, S., Nielsen, L.: Using Storytelling to Improve Scenarios. In: Proceedings of the IADIS International Conference Information Systems, Barcelona, Spain, February 25-27 (2009)

10. McGraw, K.L., Harbison, K.: User-Centered Requirements: The Scenario-Based Engineering Process. Lawrence Earlbaum Ass., New Jersey (1997)

11. Karat, C.-M., Karat, J.: Some Dialogues on Scenarios. SIGCHI Bulletin 24(4), 7-17 (1992)

12. Suri, J.F., Marsh, M.: Scenario Building as an Ergonomics Method in Consumer Product Design. Applied Ergonomics 31(2), 151-157 (2000)

13. Nardi, B.A.: The Use of Scenarios in Design. SIGCHI Bulletin 24(4), 13-14 (1992)

14. Rosson, M.B., Carroll, J.M.: Usability Engineering. Morgan Kaufmann Publishers, San Francisco (2002)

15. Quesenbury, W.: Storytelling and Narrative. In: Pruitt, J., Adlin, T. (eds.) The Personas Lifecycle, pp. 520-555. Elsevier, San Francisco (2006)

16. Ryan, M.-L.: Narrative as Virtual Reality: Immersion and Interactivity in Literature and Electronic Media. The Johns Hopkins University Press, Baltimore (2001)

17. Boje, D.M.: The Storytelling Organization: A Study of Story Performance in an OfficeSupply Firm. Administrative Science Quarterly 36, 106-126 (1991)

18. Abbott, H.P.: The Cambridge Introduction to Narrative. The Cambridge University Press, Cambridge (2002)

19. Polkinghorne, D.E.: Narrative Knowing and the Human Sciences. State University of New York Press, N.Y. (1988)

20. Bruner, J.: Acts of Meaning. Harvard University Press, London (1990)

21. Bordwell, D.: Narration in the Fiction Film. Routledge, London (1997)

22. Mandler, J.M.: Stories: The Function of Structure. In: The Annual Convention of the American Psychological Association, CA, Anaheim, 91st, August, pp. 26-30 (1983)

23. Orlikowski, W.J., Iacono, C.S.: Research Commentary: Desperately Seeking the "IT" in IT Research - A Call to Theorizing the IT Artifact. Information Systems Research 12(2), 121-134 (2001) 